\title{
Influence of Meta-cognitive Training and Cognitive Styles on Numeracy Achievement of Nigerian Pupils' in Computer-mediated Classrooms
}

\author{
Taiwo Oladunni Gbenga-Akanmu ${ }^{1, *} \&$ Philip Olu Jegede ${ }^{1}$ \\ ${ }^{1}$ Institute of Education, Obafemi Awolowo University, Ile-Ife, Nigeria \\ *Correspondence: Institute of Education, Obafemi Awolowo University, Ile-Ife, Nigeria. Tel: 803-744-5405. E-mail: \\ pojegede@gmail.com
}

Received: January 19, 2019

Accepted: February 15, 2019 Online Published: February 20, 2019

doi:10.5430/wje.v9n1p221

URL: https://doi.org/10.5430/wje.v9n1p221

\begin{abstract}
The study examined the effect of meta-cognitive training on field-dependent and field-independent primary school pupils' knowledge of numeracy concepts. It also investigated the moderating effects of sex on meta-cognitive training of the two categories of learners on performance in numeracy. In addition, it investigated the moderating effects of sex on the outcome of meta-cognitive training of the two categories of learners' in a computer-mediated classroom on retention of learned numeracy concept. These were with a view to providing information on how meta-cognitive training affected numeracy achievement of Nigerian pupils' in computer-mediated classrooms. The study adopted the pretest, posttest, control group experimental design. The study population comprised primary school pupils and the sample comprised 39 primary three pupils from two schools in two educational zones. The schools were purposely selected because of availability of computer facilities in their schools. Three research instruments were used for this study namely: Meta-cognitive Training Manual (MCTM), Pupils' Achievement Test on Numeracy (PATON) (response instrument) and One treatment instrument which is Computer Numeracy Instructional Package for Primary School Children $\left(\mathrm{CNIP}^{2} \mathrm{SC}\right)$ (stimulus instrument). Data obtained were analyzed using descriptive and inferential statistics of Analysis of Covariance (ANCOVA). The results showed that meta-cognitive training had significant effect on performance of learned numeracy concepts of field-dependent and field-independent learners' $(F=11.16 ; p<0.05)$, sex had no significant effect on performance in numeracy between the groups of learners $(F=0.14 ; p>0.05)$. It was also obtained that there was no moderating effect of sex on retention of numeracy performance of the two categories of learners $(F=0.22 ; p>0.05)$.
\end{abstract}

Keywords: meta-cognitive training, numeracy, cognitive styles, achievement, computer-mediated

\section{Introduction}

Education is the foremost means through which potentials are explored. Skills acquired, aptitudes and competences that are necessary for coping with life are realized (Achuonye \& Ajoku, 2003). In addition, education aims at producing individuals who are morally, physically, mentally and socially balanced. An educated person is not only expected to acquire knowledge, but also to demonstrate those worthwhile characteristics of an educated person. In recognition of the importance of education, governments of all nations strive hard to provide qualitative education to the citizens as qualitative education guarantees sustainable technological, economic, cultural and socio-political development of a nation. It could be said that the future of a nation is in jeopardy without a strong educational base.

Primary education is the foundation of all learning including that of Mathematics, which is a compulsory subject, offered in Nigerian primary and secondary schools and is taught daily in all the schools or at least four times in a week. However, majority of Nigeria school children generally dread Mathematics, (Chinyere \& Uche, 2013). Most of them consider it complex and abstract (Chinyere et al., 2013). Worse still, many children do not immediately see the use of the subject in their day-to-day living and to the world of work and so wonder why they should be troubled with the subject.

Moreover, Mathematics is an exact and precise body of knowledge. The procedure by which the final answer is arrived at may be different, but the answer remains the same. Accuracy and exactness are thus the pillars on which Mathematics stands. The knowledge of Arithmetic helps a child learn the value of accuracy and adopt it as a principle 
of life. It promotes the habit of logical, systematic and orderly arrangements of facts in the individual learner. Kravitz (2013) stated that Mathematics is the one skill everyone needs to master in life. According to him, even if it is the only one, one will at least be able to live without being cheated, robbed or abused. In his view, people need Mathematics in their everyday lives and cannot live or survive without it. Apart from the importance of higher level Mathematics in bringing about the realization of the goals of science and technology for a country, Mathematics taught at the lower levels of Nigeria educational system are also there to help build reasonable, thoughtful and productive citizens.

To apprehend poor performance in Mathematics, computer-mediated strategies have been employed and computer has been integrated into the classroom. Fengfeng (2008) postulated that the introduction of computer may have effect on the performance in Mathematic at $4^{\text {th }}$ and $5^{\text {th }}$ grades in the primary schools. To apprehend the problem associated with teaching and learning of Mathematics, recent advances in teaching have employed Computer-aided instructions in the classrooms and in Mathematics learning in particular. The use of computer in education is expected to benefit all groups of learners, that is, field-dependent or field independent. (Gbenga-Akanmu \& Jegede, 2015).

Furthermore, there is a growing evidence that metacognition is an important component of intelligence and cognition which influences academic success. Brown (1987) refers to metacognition as one's knowledge and control of one's cognitive system". Flavell (1976) was the first who introduced the term "meta memory" as the knowledge that individuals have about their memory processes. The term "meta" refers to second order knowledge or function, hence, the term "metacognition" was used. Flavell (1979) expanded the concept to include the meta-cognitive knowledge and regulation of cognition. Furthermore, he suggested a model of metacognition and cognitive monitoring in describing the actions of and interactions among four classes of phenomena: meta-cognitive knowledge, meta-cognitive experience, goals or tasks and actions or strategies.

The major categories of these factors or variables are person, task and strategy. The person category encompasses everything that a person believes about the nature of him/herself and other people as cognitive processors. It refers to the kind of acquired knowledge and beliefs that concern what human beings are like to cognitive organisms. The task category concerns the information about the object available to a person during a cognitive enterprise. Thinkers must recognize that different tasks entail different mental operations (Demetriou, 2000).

Pitchers (2002) defines cognitive style as the relatively stable strategies, preferences and attitudes that determine an individual's typical modes of perceiving, remembering and problem solving. Cognitive styles are thought of as the modes by which learners' approach, acquire and process information, as well as including the consistent ways in which an individual memorizes and retrieves information (Witkin and Goodenough, 1981). Messick (1996) opined that cognitive learning style goes beyond learning to involve an individual's psychological and social functioning. The predominant approach to this subset of cognitive style has been the construct of 'field dependence and field independence'. These two constructs entail the way individuals attend to, recognize and structure perceptual patterns. They reflect the way pattern recognition is processed and retained in memory. The whole approach involves an individual's ability to perform perceptual analytic type tasks (Riding \& Cheema, 1991) and it is derived from the substantive work of Witkin, Oltman, Raskin and Karp (1971). Cognitive style in learners remains a key factor in the area of education. If a pupil cognitive style is been identified at the early stage of education, the chances are improved that the pupil will have a more positive learning experience and perform better, feel more positive about solving difficulty task like numeracy which is one of the basic skills and important that learners are expected to possess and also feel more comfortable when working with one another.

A child's poor performance in numeracy is not necessarily due to the child's lack of efforts, or to failings on the part of parents or teachers. On the other hand, difficulties in numeracy are not purely innate or immutable. There are very large differences in performance between children in different countries, suggesting a very important influence of the environment. In such a situation, interventions are possible to solve the problem. It is desirable that interventions such as meta-cognitive training should take place at an early stage. People who, to varying degrees, lacked opportunity for or interest in learning numeracy in school may learn later as adults (Evans, 2000). In any case, interventions are easier and less painful if they take place before mathematics anxiety set in. Therefore, while it is never too late to intervene to help with numeracy difficulties, interventions may be particularly effective if they are early especially meta-cognition which is an awareness of one's own mental strategies and level of knowledge is often regarded as particularly important to numeracy which is the intervention used in this study.

The following objectives guided the study:

a. examine the effect of meta-cognitive training on field-dependent and field-independent primary school pupils' knowledge of numeracy concepts; 
b. investigate the moderating effects of sex on meta-cognitive training of the two categories of learners on performance in numeracy; and

c. investigate the moderating effects of sex on the outcome of meta-cognitive training of the two categories of learners' in a computer-mediated classroom on retention of learned numeracy concept.

\section{Theoretical Framework}

The theoretical frameworks on which this study is premised are Flavell's Metacognition Theory (1971). Flavell was influenced by the work of Jean Piaget. Piaget's theory had found its way into the conventional wisdom of metacognition of intentionality. Intentionality pre supposes thinking that is deliberate and goal-directed, and involves planning a sequence of actions and Piaget Theory of Cognitive Development (1936) as there exist a relationship between the two theories in terms of child development which is in stages and both theories is a gradual process and goal directed.

\section{Method}

The study adopted the pretest, posttest, control group quasi-experimental design. The study population was made up of primary school pupils in Nigeria and the sample comprised 39 primary three pupils in two intact classes with an average age of 8 years in the selected zones. The study adopted multistage sampling techniques. From the six Educational Zones in Osun State in Nigeria, two educational zones which constitute one-third of the total number of educational zones in the state were randomly selected. One school was purposively selected from each of the two educational zones based on availability of computers in the schools which was used for both the experimental and control group.

Three research instruments were used for this study namely: Meta-cognitive Training Manual (MCTM), Pupils' Achievement Test on Numeracy (PATON) (response instrument) and one treatment instrument which is Computer Numeracy Instructional Package for Primary School Children (CNIP2SC) (stimulus instrument).

(i)

Meta-cognitive Training Manual (MCTM). This instrument was adapted from a model developed by Teong Su Kwang (2000) which was for meta-cognitive training with the experimental group. It comprised the acronym (CRIME) Careful Reading, Re-call, Implement, Monitor and Evaluation of one's learning. The researcher used this to develop a lesson plan which was used for meta-cognitive training.

Pupils' Achievement Test on Numeracy (PATON) The Pupils' Achievement Test on Numeracy (PATON) was designed by the researcher to measure the pupils' understanding and knowledge of numeracy concepts (Number and Numeration, Basic operations and Measurement) using the Primary Three Scheme of Work. The test also measures the contribution of logical-mathematical, visual-spatial and verbal-linguistic intelligence in their knowledge of numeracy concepts. The PATON was divided into three sections namely: quantitative reasoning, mental sum and measurement. The first section contains 10 quantitative reasoning questions; the second section has 5 mental sums questions while the third section has 10 measurement questions. So for this study the PATON consists of a total of 25 questions. Each question answered correctly was awarded 1 mark, thus the total obtainable score was 25. The PATON was conducted prior to the intervention which was the meta-cognitive training with the experimental group as pre-test while the PATON was conducted prior to the teaching of numeracy in a computer-mediated classroom with the control group as pre-test. The same PATON test was administered on the participants after the teaching of numeracy with the two groups in a computer-mediated classroom (post-test). The test was repeated two weeks to measure retention of numeracy concepts taught via meta-cognitive training and computer-mediated classroom.

(iii) Computer Numeracy Instructional Package for Primary School Children (CNIP $\left.{ }^{2} S C\right)$. The Computer Numeracy Instructional Package for Primary School Children $\left(\mathrm{CNIP}^{2} \mathrm{SC}\right)$ instruction programme was developed by the researcher alongside with the scheme of work from the schools which provided a guide for the development of the package with the blueprint for teaching numeracy concepts (Numbers and Numeration, Basic Operations and Measurement). The pupils were taught numeracy using this package. The $\mathrm{CNIP}^{2} \mathrm{SC}$ had series of exercises which the pupils worked on during the exercises. The researcher served as the teacher/facilitator to the pupils in the use of the package for teaching numeracy concepts. The PATON were administered to all the participating pupils both the experimental and the 
control group as pretest in the selected schools as a pretest.

In the second step, meta-cognitive training was conducted for 3 weeks, twice a week with 30 minutes' duration for each meta-cognitive training session with the experimental group (primary three pupils). The training was on how they could train themselves in answering numeracy questions. Meta-cognitive was introduced to the participants; practical examples were given with real life items in the class for better understanding of what it means to think, recall, put into practice what has been taught and apply it in a new or similar situation. The researcher gave class work to the participants and went through their work to make sure they followed the instructions and got the idea correctly.

The third step was teaching numeracy concepts with all the participants both at the experimental and the control group using $\left(\mathrm{CNIP}^{2} \mathrm{SC}\right)$ for six weeks. The researcher used the Numeracy Instructional Package for Primary School Children to teach the participants in a computer environment. Which means the chalk method was not used but the teaching was done using computers. At the end of the sixth week, a posttest was administered using the PATON on all the participants.

At the last step of the research, the participants were left for two weeks after which the researcher came back for retention test. This was exactly after two weeks of posttest on the two groups. The research experiment lasted for a period of eight weeks in total. The data collected were analyzed using descriptive and inferential statistics of Analysis of Covariance (ANCOVA) statistical technique.

\section{Results}

To examine the effect of meta-cognitive training on field-dependent and field-independent primary school pupils' knowledge of numeracy concepts a pre-test was conducted on the participants irrespective of their cognitive styles prior to the intervention which was the meta-cognitive training. From Table 1, the main effect indicated that there exists a significant $(F=11.16 ; p<0.05)$ difference in the pupils' performance. Also, the results showed that covariate (pre-test score) significantly $(p<0.05)$ predict pupils' performance. Based on this, pre-test score accounted for some variation in the pupils' performance. Controlling for the effects of the covariate (pre-test), result indicated that the main effect of cognitive style is significant $(p \leq .0 .05)$ indicating that the significant difference that existed in the pupils' performance did not occur by chance. Furthermore, the partial eta square for the group embedded figure test is 0.12 . This showed that (CGEFT) (field-dependent and independent) accounted for $12 \%$ of the variation in the pupils' performance.

To investigate the moderating effects of sex on meta-cognitive training of the two categories of learners on performance in numeracy, a pre-test was conducted on the participants and were also categorized into female and male (field-dependent and field-independent prior to the intervention which was the meta-cognitive training. Table 2 shows the relationship between the dependent variable (post-test score), group (independent variable), gender and pre-test score as covariates. There is a significant $(p<0.05)$ difference in the pupils' performance as a result of the main effect. The results also showed that sex has no significant influence $(F=0.14 ; p>0.05)$ on pupils' performance. However, pre-test score significantly $(p<0.05)$ predicts pupils' performance. The result further showed that when the effects of the covariates (sex and pre-test score) were removed, the main effect of the (field-dependent and independent) is significant $(p<0.05)$ indicating that the significant difference that existed in the pupils' performance is also influenced by the (field-dependent and independent). The partial eta square for the intervention group is 0.15 . This showed that intervention group explained $15 \%$ of the variation in performance. With the consideration given to sex and pre-test, it was evident that cognitive style had significant effect on pupils' performance. Therefore, sex as a moderating effect does not have a significant effect on the performance of the pupils.

To investigate the moderating effects of sex on the outcome of meta-cognitive training of the two categories of learners' in a computer-mediated classroom on retention of learned numeracy concept, a posttest was administered on all the participants at the end of the intervention and the participants were left for two weeks after which the retention test was conducted. Table 3 reveals the linear relationship between the dependent variable (retention score), group (independent variable_and sex, pre-test score and post-test as covariates. The performance of the two groups (experimental and control) before and after post-test (retention) were examined. The main effect reveals a significant $(p<0.05)$ difference in the pupils' performance. The result also showed that covariates (sex, pre-test and post-test scores) significantly $(p<0.05)$ predict pupils' performance. Sex was however found not significantly $(F=2.16$; $p>0.05$ ) predicts pupils' performance. Therefore, the higher mean score among those that were exposed to intervention did not occurred by chance; it was as a result of the intervention (meta-cognitive training). This is explained by the partial eta square for the intervention group which reveals an explanation of $15 \%$ of the variation in 
the pupils' performance. Therefore, with the consideration given to sex, pre-test and post-test scores, it was obvious that intervention had effect on pupils' performance while sex did not.

Table 1. Analysis of Covariance Showing the Effect of Meta-Cognitive Training on Field-Dependent and Field-Independent Primary School Pupils' Knowledge of Numeracy Concepts

\begin{tabular}{lllllll}
\hline Source & Partial SS & Df & MS & F & p-value & Partial eta2 \\
\hline Model & 628.1107 & 15 & 41.8740 & 21.78 & $0.0134^{*}$ & \\
Group & 473.1242 & 1 & 473.1242 & 13.15 & $0.0023^{*}$ & \\
Field-dependent and independent & 518.0231 & 1 & 518.0231 & 11.16 & $0.0114^{*}$ & 0.12 \\
Pre-test score & 617.8124 & 14 & 44.1294 & 2.93 & $0.0108^{*}$ & \\
Residual & 346.2482 & 23 & 15.0542 & & & \\
Total & 974.3590 & 38 & 125.6410 & & & \\
\hline
\end{tabular}

Field survey, 2017

*significant at 0.05 level of significance

Table 2. Analysis of Covariance Showing the Effect of Sex of Meta-Cognitive Training of the two Categories of Learners on Performance in Numeracy

\begin{tabular}{lllllll}
\hline Source & Partial SS & Df & MS & F & p-value & Partial eta2 \\
\hline Model & 630.2481 & 16 & 39.3905 & 2.52 & $0.0228^{*}$ & \\
(CGEFT) & 28.0300 & 1 & 28.0300 & 4.00 & $0.0145^{*}$ & 0.15 \\
Sex & 2.1374 & 1 & 2.1374 & 0.14 & 0.7152 & \\
Pre-test score & 609.2520 & 14 & 43.5180 & 2.78 & $0.0155^{*}$ & \\
Residual & 344.1108 & 22 & 15.6414 & & & \\
Total & 974.3590 & 38 & 25.6410 & & & \\
\hline
\end{tabular}

Field survey, 2017

*significant at 0.05 level of significance

Table 3. Analysis of Covariance Showing the Moderating Effect Sex on the Outcome of Meta-Cognitive Training of the Two Categories of Learners in a Computer-Mediated Classroom on Retention of Learned Numeracy Concept

\begin{tabular}{lllllll}
\hline Source & Partial SS & Df & MS & F & p-value & Partial eta2 \\
\hline Model & 582.6707 & 30 & 19.4224 & 4.68 & $0.0141^{*}$ & \\
Group & 12.6838 & 1 & 12.6838 & 2.16 & $0.0269^{*}$ & 0.15 \\
Sex & 0.9320 & 1 & 0.9320 & 0.22 & 0.6484 & \\
Pre-test score & 158.7750 & 14 & 11.3411 & 2.73 & 0.0783 & \\
Post-test score & 211.3063 & 14 & 15.0933 & 3.63 & $0.0362^{*}$ & \\
Residual & 33.2267 & 8 & 4.1533 & & & \\
Total & 615.8974 & 38 & 16.2078 & & & \\
\hline
\end{tabular}

Field survey, 2017

*significant at 0.05 level of significance

\section{Discussion}

The result of ANCOVA on the hypothesis that there is no significant effect of meta-cognitive training on field-dependent and field-independent primary school pupils' knowledge of numeracy concepts was rejected since the results showed a significant effect of meta-cognitive training on performance of learned numeracy concepts of field-dependent and field-independent learners. The findings of this study corroborate the studies of Ahmady and Yamini (2013) who investigated the relationship between field-dependent and field-independent listening comprehension strategy and the use of meta-cognitive with Iranian students observed that field-independent students performed better than their field-dependent counterparts which showed that cognitive style has significant influence on pupils' performance.

In addition, the finding of this study agreed with Tinajero, Lemos, Araujo Ferraces and Paramo (2012) studies with Brazilian $1^{\text {st }}$ year university students that discovered that cognitive and meta-cognitive strategies were used 
frequently by field-independent learners. It was found that field-dependent students perform poorly than field-independent students in academic achievement. It also lend support to Harandi V, EslamiSharbabaki $\mathrm{H}$, Ahmadi Deh M, DarehkordiA (2013) who worked on The Effect of Metacognitive Strategy Training on Social Skills and Problem-Solving Performance and found a significant difference between field-dependent and field-independent performance.. These studies were done with secondary school and university students while this present study was done with primary school pupils and also which indicates that cognitive styles accounts for performance at all levels of education.

The finding of this study negated the finding of another study with 80 participants, Kheirzadeh and Kassaian (2011) concluded that field-dependence/independence did not affect listening comprehension in general and listening comprehension sub-skills in special. The reason for this is not immediately apparent but was perhaps due to difference in the population, geographical location and the subject used in the study.

The hypothesis that postulated that there is no moderating effect of sex of meta-cognitive training of the two categories of learners on performance in numeracy, the hypothesis was not rejected; hence, there is no moderating effect of sex on performance in numeracy between the groups of learners. This finding corroborated the findings of Gbenga-Akanmu and Jegede (2015) that worked on the effect of computer-based instruction on the performance in numeracy of field-dependent and field-independent primary school pupils and found that; there was no significance moderating effect of sex on numeracy performance of field-dependent and field-independent groups of learners. Also Ahmed Hassan Hemdan Mohamed (2012) study of the relationship between Metacognition and Self-regulation in Young Children found no significance moderating effect of sex on their performance even though the study was not on Mathematic.

Meanwhile, the finding of this study negated the finding of Adeneye and Awofala (2011). Is gender a factor in mathematics performance? Their study concluded that there was a significant difference between the mathematics performance of male and female students. The findings of this study also did not agree with the studies of Shojoe and Leila (2013) that conducted a research to investigate the relationship between cognitive styles (field-dependent and filed-independent) and academic achievement in male and female students of Bahaman Islamic Azad university found out that there was a significance positive relationship between male and female students' (field-dependent and filed-independent) and their academic achievement. This may be due to the level of students used for their own studies and the environments in which the studies were carried out. This study used primary school pupils while they used secondary school students. It is therefore noted here that cognitive styles is a significant predictor of performance of students at all levels of education and also it cut across the nation.

Furthermore, the hypothesis that postulated that there is no moderating effect of sex on the outcome of meta-cognitive training of the two categories of learners in a computer-mediated classroom on retention of learned numeracy concept. The result of ANCOVA showed that there was no moderating effect of sex on retention of numeracy performance of the two categories of learners, thus, the hypothesis was not rejected. This result corroborated the findings of Spencer (2004) Spencer study on engagement with mathematics courseware in traditional and online learning environments: Relationship to motivation, achievement, gender, and gender orientation found out that sex as a moderating variable has no effect on students' performance. It is also in line with the studies of Gbenga-Akanmu and Jegede (2015) work on the effect of computer-based instruction on the performance in numeracy of field-dependent and field-independent primary school pupils and found out that; there was no significant effect of sex on retention of numeracy performance of the two categories of learners. This finding also corroborate the findings of Siti and Corebima (2014) study on learning strategy equalizing students' achievement, meta-cognitive, and critical thinking skills revealed that the combination of learning strategy and concept mapping is inclined having a higher potency in enhancing the achievement of female and male students in terms of the meta-cognitive skill, the critical thinking ability, the cognitive learning result, and the retention.

Learning and recalling activities can be improved if the students are able to integrate the information obtained from both verbal and presentation, for example meta-cognitive training. Based on the above discussion, related to the dependent variables, such as the meta-cognitive skill, the cognitive learning result, and the retention, the achievement of female and male students is the same. Both female and male students experiencing meta-cognitive training are inclined achieving good scores in their retention text.

Based on the findings of this research work, it was concluded that there was significant effect of meta-cognitive training on performance of learned numeracy concepts irrespective of their cognitive style. Furthermore, there was no moderating effect of sex on performance in numeracy of the two categories of learners. Overall observation showed sex as a moderating effect has no significant effect on retention of numeracy performance of the two 
categories of learners. Researches that have been done about metacognition are persuasive evidences to encourage the use of metacognition in learning and teaching process.

\section{References}

Achuonye, K. A., \& Ajoku, L. I. (2003). Foundations of curriculum development and implementation. Port Harcourt: Pearl Publishers.

Adeneye O., \& Adeleye Awofala. (2011). Is gender a factor in Mathematics Performance among Nigerian Secondary School Students within varying School Organization and Location? International Journal of Mathematics Trends \& Technology, 2(3).

Ahmady, A., \& Yammini, M. (2013). Relationship between field dependence/independence and listening comprehension strategy use by female Iranian English majors. Retrieved 08 Feb from http://www.noormags.com/view/fa/articlepage/82224

Ahmadzaide, L., \& Shojoe, M. (2013). Investigating the Relationship between Cognitive Style (Field dependence/Independence and Academic Achievement in Male and Female Students of Behbahn Islamic Azad University. Journal of life Science. Biomed, 3(3), 245.

Brown, A. (1987). Metacognition, executive control, self-regulation and other more mysterious mechanisms. In Frann Weinert \& Rainer Kluwe (Eds.), Metacognition, Motivation and Understanding (pp65-115). London: LEA.

Chinyere F. O., \& Uche S. A. (2013). Nigeria school children and Mathematics phobia: How the Mathematics teachers can help. American Journal of Educational Research, 17, 247-251.

Demetriou, A. (2000). Organization and development of self-understanding and self-regulation. In Monique Boekaerts, P. Pintrich \& M. Zeidner (Eds.), Handbook of self-regulation (209-251). USA: Academic press. https://doi.org/10.1016/B978-012109890-2/50036-6

Evans, J. (2000). Adults' Mathematical Thinking and Emotions: A Study of Numerate Practice. London: Routledge.

Fengfeng, K. (2008). A case study of computer gaming for math: Engaged learning from game play? (Doctoral dissertation, University of New Mexico) (pp. 1609-1620). Computers and Education: https://doi.org/10.1016/j.physletb.2003.10.071

Flavell, J. H. (1976). Metacognitive aspects of problem solving. The nature of intelligence, 12, 231-235.

Flavell, J. H. (1979). Metacognition and cognitive monitoring: A new area of cognitive developmental inquiry. American Psychologist, 34(10), 906-911. https://doi.org/10.1037/0003-066X.34.10.906

Gbenga-Akanmu, T. O., \& Jegede P. O. (2015). Effect of Computer-based Instruction on Performance in Numeracy of Field-dependence and Field-independence Primary School Pupils in Ile-Ife, Osun State. American Academic \& Scholarly Research Journal, 7(5), .

Harandi V., Eslami Sharbabaki H., Ahmadi Deh M., \& Darehkordi A. (2013). The Effect of Metacognitive Strategy Training on Social Skills and Problem-Solving Performance. Psychol Psychother, 3, 121. https://doi.org/10.4172/2161-0487.1000121

Kheirzadeh, S., \& Kassaian, Z. (2011). Field- dependence/independence as a factor affecting performance on listening comprehension sub-skills: the use of Iranian EFL learners. Journal of Language Teaching and Research, 2(1), 188-195. https://doi.org/10.4304/jltr.2.1.188-195

Kravitz, C. (2013). Why Maths is important. Retrieved $10^{\text {th }}$ July, 2013 from www.shdeshare.net/chelseakravitz/why-math-is-important

Messick, S. (1996). Bridging Cognition and Personality in Education: the role of style in performance and development, European Journal of Personality, 10, 353-376. https://doi.org/10.1002/(SICI)1099-0984(199612)10:5\%3C353::AID-PER268\%3E3.0.CO;2-G

Pithers, R. T. (2002). Cognitive learning styles: A review of field dependence-independent approach. Journal of Vocational Education and raining, 13(4), 267-279.

Riding, R., \& Cheema, I. (1991). Cognitive Styles - an overview and integration. Educational Psychology, 11, 193-216. https://doi.org/10.1080/0144341910110301 
Siti R., \& Corebima A. D. (2014). Learning Strategy Equalizing Students’ Achievement, Meta-cognitive and Critical thinking Skills. American Journal of Educational Research, 2(8), 577-584. https://doi.org/10.12691/education.2-8-3

Spencer, D. J. (2004). Engagement with mathematics courseware in traditional and online learning environments: Relationship to motivation, achievement, gender, and gender orientation. Unpublished dissertation submitted to the Faculty of Graduate School of Emory University, in partial fulfillment of the requirement for the degree of Doctor of Philosophy. Retrieved March 17, 2007, from http://www.des.emory.edu/mfp/SpenceDissertation2004.pdf

Teong, S. K. (2000). The effect of meta-cognitive training on mathematical word-problem solving. Journal of Computer Assisted Learning, 19, 46-55. https://doi.org/10.1046/j.0266-4909.2003.00005.x

Tinajero, C., Lemos, S., Araujo, M., Ferraces, M. J., \& Paramo, M. F. (2012). Cognitive style and learning strategies as factors which affect academic achievement of Brazilian University students. Piscol Reflex Crit, 25(1), 105-113. https://doi.org/10.1590/S0102-79722012000100013

Witkin, H. A., Oltman, P. K., Raskin, E., \& Karp, S. A. (1971). A manual for the Embedded Figures Test. Palo Alto, CA: Consulting Psychologists Press.

Witkin, H., \& Goodenough, D. (1981). Cognitive styles: Essence and Origins: Field Dependence and Field Independence. Psychological Issues, 51, 1-141. 